\title{
Tool wear estimation in turning of Inconel 718 based on wavelet sensor signal analysis and machine learning paradigms
}

\author{
Tiziana Segreto ${ }^{1,2}\left(\mathbb{C} \cdot\right.$ Doriana D'Addona $^{1,2} \cdot$ Roberto Teti $^{1,2}$
}

Received: 27 July 2020 / Accepted: 5 October 2020 / Published online: 19 October 2020

(c) The Author(s) 2020

\begin{abstract}
In the last years, hard-to-machine nickel-based alloys have been widely employed in the aerospace industry for their properties of high strength, excellent resistance to corrosion and oxidation, and long creep life at elevated temperatures. As the machinability of these materials is quite low due to high cutting forces, high temperature development and strong work hardening, during machining the cutting tool conditions tend to rapidly deteriorate. Thus, tool health monitoring systems are highly desired to improve tool life and increase productivity. This research work focuses on tool wear estimation during turning of Inconel 718 using wavelet packet transform (WPT) signal analysis and machine learning paradigms. A multiple sensor monitoring system, based on the detection of cutting force, acoustic emission and vibration acceleration signals, was employed during experimental turning trials. The detected sensor signals were subjected to WPT decomposition to extract diverse signal features. The most relevant features were then selected, using correlation measurements, in order to be utilized in artificial neural network based machine learning paradigms for tool wear estimation.
\end{abstract}

Keywords Inconel $718 \cdot$ Tool wear $\cdot$ Multiple sensor monitoring $\cdot$ Wavelet packet transform $\cdot$ Machine learning $\cdot$ Artificial neural networks

\section{Introduction}

In modern machining processes, tool wear estimation is a crucial requirement to prevent machine tool failure and to produce parts with the required high quality. During machining operation, the employment of worn cutting tools can cause poor surface finish and insufficient dimensional accuracy of the product as well as unexpected catastrophic tool failure events. Moreover, cutting tool health tends to deteriorate more rapidly when the workpiece hardness is higher [1].

In the last years, the notable increase in the demand for materials with high strength and temperature resistivity in aerospace and gas turbine industries has led to an extensive use of nickel-based alloys. These alloys provide properties

Tiziana Segreto

tsegreto@unina.it

1 Department of Chemical, Materials and Industrial Production Engineering, University of Naples Federico II, Piazzale Tecchio 80, 80125 Naples, Italy

2 Fraunhofer Joint Laboratory of Excellence on Advanced Production Technology (Fh J_LEAPT UniNaples), Piazzale Tecchio 80, 80125 Naples, Italy of high strength, excellent resistance to corrosion and oxidation, and long creep life at elevated temperatures but are classified as a hard-to-machine materials [2-4].

Inconel 718 is a nickel-based alloy largely utilized to manufacture parts of nuclear reactors, gas turbines, rocket motors, spacecraft, pumps, tooling systems, etc. It combines corrosion resistance and high strength with outstanding weldability, including resistance to post-weld cracking. Moreover, this alloy has excellent creep-rupture strength at temperatures up to $700{ }^{\circ} \mathrm{C}$. Besides these excellent properties, the machinability of Inconel 718 faces challenges in terms of high cutting forces and high temperature growth, built-up edge formation, strong work hardening, and rapid tool wear development $[5,6]$.

Rapid tool wear is a critical factor in terms of quality of the machined parts (with risk of workpiece scrap), short tool life, increase in energy consumption and tooling cost $[2,7,8]$.

As a practical way out, many manufactures have chosen to utilize lower cutting parameter values and replace the cutting tool before approaching the critical wear limits [9].

Generally, tool wear measurements are performed by interrupting the machining process and making a judgment 
on tool wear level using offline inspection techniques such as optical microscope, profilometer, camera, etc.[10]. These direct measuring methods are generally carried out by the operator who stops the machining operation periodically with significant waste of production time and cost.

Today's tool condition monitoring (TCM) systems can be applied for the indirect measurement of tool wear during machining using sensorial instrumentation able to detect sensor signals related to tool wear development.

Numerous papers have been published on TCM during machining operations using diverse sensors such as dynamometer, accelerometer, motor load current, acoustics emission, temperature, vibrations, etc.; many of these research works are reviewed in [11-13].

An effective intelligent TCM system must be able to perform different functions: sensor signal data acquisition, sensor signal processing, features extraction and selection, and pattern recognition for decision making. The acquired raw sensor signals contain a lot of useless and/or misleading information, including noise and signal contamination, and need to be processed by filtering, amplification, analogto-digital conversion, and segmentation procedures. Then, sensor signal features can be extracted in the time domain, frequency domain, and time-frequency domain [14]. In the time domain, statistical analysis, singular spectrum analysis and principal component analysis are widely used while the fast Fourier transforms and power spectrum density are the most common methods in the frequency domain.

To simultaneously analyze the signals in the time and in the frequency domains, wavelet transform (WT) has been largely applied to TCM [15]. Olortegui-Yume and Kwon [16] studied the crater wear development using wavelet-filtered images to identify the tool wear mechanisms in turning processes applied to AISI 1045 steel bars. In [17], a discrete wavelet transform was applied to turned surface images for tool flank wear prediction. A review of wavelet analysis applications for TCM is presented in [18].

In order to reduce the high number of features extracted from the analyzed sensor signals, it is necessary to select a subset of relevant features that maintains the correlation with the tool state. Various feature selection algorithms have been proposed in the literature such as Pearson correlation coefficient, Fisher's linear discriminant analysis, ridge regression, and least absolute shrinkage and selection operator [19].

Artificial intelligence (AI) and machine learning (ML) methods $[20,21]$ play a key role in the improvement of modern TCM systems [14, 22, 23]. In particular, several researchers have studied and applied diverse AI and ML methods for TCM such as fuzzy clustering approaches [24], genetic algorithms [25], Gaussian mixture models [26], neuro-fuzzy techniques $[27,28]$, self-organizing feature maps [29], hidden Markov models [30], support vector machine [31]. Artificial neural networks (ANNs) based ML paradigms are very often applied due to their high capability in pattern recognition procedures.

As regards TCM during machining of Inconel 718, several research papers studied the diverse aspects of the cutting tool (geometry, material, surface, coatings) for the selection of the adequate tool to employ by minimizing the machining costs $[2,6,10,32,33]$. Other papers reviewed the surface integrity characteristics of machined nickel-based alloys by evaluating the influence of diverse cutting parameter values [3, 34-36].

However, the correlation of the acquired sensorial data with tool wear during machining of Inconel 718 for tool life prediction is little studied. In the recent literature, a tool wear monitoring system based on vibration and force sensors was utilized in [37] during hard turning of Inconel 718. The experimental trials were performed until the tool was completely worn out. The study showed that the force data are quite useful to establish a strong correlation between cutting force and tool wear.

In [38] the relationship between the tool wear evolution and the changes of the three cutting force components was studied during turning of Inconel 718 , showing that the passive force is more representative due to the fact that the tool corner wear is associated with a strong ploughing action.

Kene and Choudhury [39] implemented a tool health monitoring system using multiple sensors signals in hard turning, presenting a novel analytical model of sensor data fusion. The results of this research confirm the effectiveness of using a fusion function over single sensor-based approaches.

A new cutting tool holder was designed in [40] to break continuous chips during turning of Inconel 718 . The effect of the holder was examined by analyzing the cutting forces, cutting temperatures, surface roughness, and tool wear behaviour. A significant reduction in tool wear was observed using a high machining speed, a low feed rate, and high depth of cut.

In this paper, the tool wear estimation during experimental turning trials on Inconel 718 was performed by using an advanced sensor procedure, based on wavelet sensor signal analysis, and machine learning paradigms for decision making. Cutting force, acoustic emission, and vibration acceleration sensor signals were detected and processed. Cutting tool flank wear measurements were performed after each 2-min of turning in order to evaluate the tool condition. The preprocessed sensor signals were subjected to wavelet packet transform (WPT) decomposition in order to extract time-frequency domain features. A Pearson's coefficient algorithm was employed to select the features most correlated with the tool wear in order to reduce the high dimensionality of wavelet features. Then, the selected features were utilized to construct diverse feature pattern vectors to feed to ANNsbased ML paradigms. The performance of ANNs models in 
estimating the tool wear level was evaluated under various combinations of the selected features.

\section{Materials and experimental set up}

The workpieces were cylindrical bars made of Inconel 718 with chemical composition and mechanical properties summarized in Table 1. Turning tests were performed on a CNC lathe using as cutting tools rhombic uncoated carbide inserts (Kennametal CNMG120408-K313) the characteristics of which are reported in Table 2.

The cutting parameters employed for the machining trials were selected according to the common cutting parameters adopted for turning of Inconel 718 (Table 3). In particular, three cutting speed values were considered: $\mathrm{v}_{\mathrm{c}}=45$, $50,55 \mathrm{~m} / \mathrm{min}$. The $45 \mathrm{~m} / \mathrm{min}$ cutting speed corresponded to the highest speed industrially employed during turning of Inconel 718, whereas the $55 \mathrm{~m} / \mathrm{min}$ cutting speed represented the maximum cutting speed for nickel-based alloys machining disclosed in the literature $[5,10,14] ; \mathrm{v}_{\mathrm{c}}=50 \mathrm{~m} /$ min was selected as intermediate cutting speed value.

Three feed rate values, $\mathrm{f}=0.100,0.125,0.150 \mathrm{~mm} / \mathrm{rev}$, were considered according to literature information $[4,5]$ and common shop floor values. The depth of cut, $d$, was kept equal to $0.3 \mathrm{~mm}$ for all turning trial conditions.

By combing the cutting parameters, 9 turning conditions were employed for cutting trials, which were repeated at least twice.

Table 1 Chemical composition and mechanical properties of Inconel 718

\begin{tabular}{llllll}
\hline \multicolumn{3}{l}{ Chemical composition (wt) } & \multicolumn{3}{c}{$\begin{array}{l}\text { Mechanical properties at room } \\
\text { temperature }\end{array}$} \\
\hline $\mathrm{Ni}$ & $50-55$ & $\mathrm{Si}$ & 0.35 & $\begin{array}{c}\text { Ultimate tensile } \\
\text { strength }\end{array}$ & $1240 \mathrm{MPa}$ \\
$\mathrm{Cr}$ & $17-21$ & $\mathrm{Mn}$ & 0.35 & $\begin{array}{c}\text { Yield strength } \\
\text { Elongation in } 50 \mathrm{~mm}\end{array}$ & 12 \\
$\mathrm{Co}$ & 1 & $\mathrm{Cu}$ & 0.3 & $\mathrm{MPa}$ \\
$\mathrm{Mo}$ & $0.65-1.15$ & $\mathrm{C}$ & 0.08 & $\begin{array}{c}\text { Elastic modulus } \\
\text { (Tension) }\end{array}$ & $211 \mathrm{GPa}$ \\
$\mathrm{Al}$ & $0.2-0.8$ & $\mathrm{P}$ & 0.015 & Hardness & $36 \mathrm{HRC}$ \\
$\mathrm{Nb}+\mathrm{Ta}$ & $4.75-5.5$ & $\mathrm{~S}$ & 0.015 & & \\
$\mathrm{~B}$ & 0.006 & $\mathrm{Fe}$ & $\mathrm{Bal}$ & & \\
\hline
\end{tabular}

Table 2 Cutting tool geometry
Table 3 Cutting parameters for turning trials

\begin{tabular}{llll}
\hline Turning parameters & & & \\
Cutting speed, $\mathrm{v}_{\mathrm{c}}(\mathrm{m} / \mathrm{min})$ & 45 & 50 & 55 \\
Feed rate, $\mathrm{f}(\mathrm{mm} / \mathrm{rev})$ & 0.100 & 0.125 & 0.150 \\
Depth of cut, $\mathrm{d}(\mathrm{mm})$ & 0.3 & & \\
\hline
\end{tabular}

Each turning trial was carried out according to a stepwise procedure with step duration equal to $120 \mathrm{~s}$. After each $120 \mathrm{~s}$ step, the operation was stopped and the tool flank wear was measured. Then, the turning steps were replicated until the maximum allowable tool flank wear, $\mathrm{VB}_{\max }=0.3 \mathrm{~mm}$, was reached.

The cutting length, $\mathrm{Z}$, corresponding to the $120 \mathrm{~s}$ step during each turning trial was calculated as follows:

From equation: $T=\frac{Z}{n \cdot f}$, it is obtained: $Z=T \cdot n \cdot f$, where $\mathrm{T}$ is the cutting time and $\mathrm{n}$ is the number of revolutions per minute. The value of $n=\frac{v_{c} \cdot 1000}{\pi \cdot D}$, where $\mathrm{v}_{\mathrm{c}}$ is the cutting speed, and $\mathrm{D}$ is the workpiece diameter. After calculating the cutting length $Z$ for each turning step, an average value $\tilde{Z}$ was considered and utilized in the CNC code: $\tilde{Z}=\frac{\sum Z_{\text {step }}}{\text { numberofsteps }}$.

A total of 36 valid turning tests were performed using three cutting speeds, three feed rates, two tool states (fresh or worn) and two test repetitions $(3 \times 3 \times 2 \times 2=36$ tests $)$ as summarised in Table 4. In particular, for each tool state (fresh or worn) 18 turning trials were carried out.

\section{Sensor signal acquisition system}

A multi-sensor monitoring system (Fig. 1) comprising three sensors of different nature (cutting force, acoustic emission, and vibration sensors) was employed during trials for tool state monitoring. In particular, the three cutting force component signals $\left(F_{x}, F_{y}, F_{z}\right)$ in the feed, the radial and the tangential directions, respectively, were acquired through a triaxial cutting force sensor (Montronix FS-ICA) clamped in a slot between tool holder and its supporting fixture. The acquired cutting force signals were then amplified using a Montronix TSFA3-ICA force amplifier.

\begin{tabular}{ll}
\hline Corner radius, $\mathrm{R} \varepsilon$ & $0.8 \mathrm{~mm}$ \\
\hline Cutting angle & $80^{\circ}$ \\
\hline Insert size, $\mathrm{D}$ & $12.70 \mathrm{~mm}$ \\
\hline Cut edge length, $\mathrm{L} 10$ & $12.90 \mathrm{~mm}$ \\
\hline Insert thickness, $\mathrm{S}$ & $4.76 \mathrm{~mm}$ \\
\hline Insert hole size, $\mathrm{D} 1$ & $5.16 \mathrm{~mm}$ \\
\hline
\end{tabular}


Table 4 Cutting parameters and test ID

\begin{tabular}{lllll}
\hline Cutting speed & Feed rate & Test ID for fresh tool & Test ID for worn tool & Repetition \\
\hline 45 & 0.100 & Test_1_fresh & Test_1_worn & 2 \\
45 & 0.125 & Test_2_fresh & Test_2_worn & 2 \\
45 & 0.150 & Test_3_fresh & Test_3_worn & 2 \\
50 & 0.100 & Test_4_fresh & Test_4_worn & 2 \\
50 & 0.125 & Test_5_fresh & Test_5_worn & 2 \\
50 & 0.150 & Test_6_fresh & Test_6_worn & 2 \\
55 & 0.100 & Test_7_fresh & Test_7_worn & 2 \\
55 & 0.125 & Test_8_fresh & Test_8_worn & 2 \\
55 & 0.150 & Test_9_fresh & Test_9_worn & 2 \\
\hline
\end{tabular}

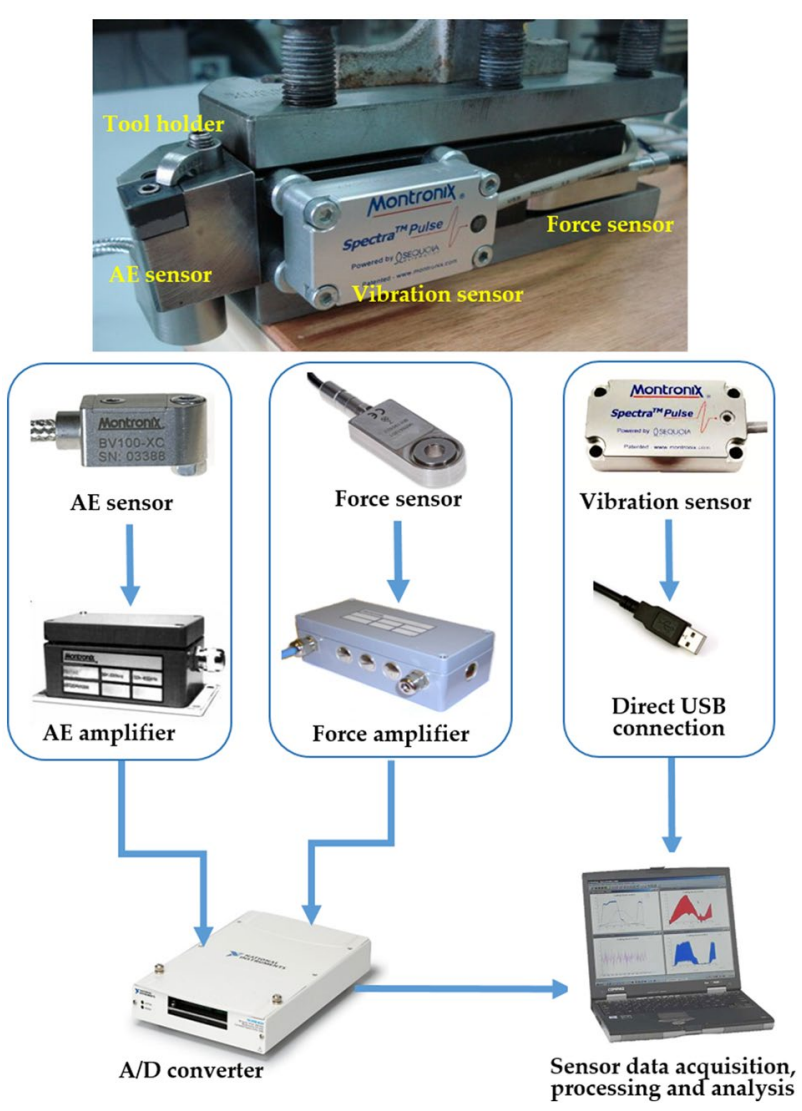

Fig. 1 Multiple sensor system comprising the cutting force, vibration and acoustic emission sensors mounted on the tool holder

The detection of the acoustic emission (AE) signals was carried out with an AE sensing unit (Montronix BV-100 Series) screwed under the head of the tool holder. The analogue AE signals were amplified by a Montronix TSVA4G AE amplifier with band-pass filtering at $50-500 \mathrm{kHz}$. Moreover, the RMS values of the AE signals were obtained using a short time constant equal to $0.12 \mathrm{~ms}$.

A multifunction data acquisition board (National Instruments USB-6221 A/D) was utilized to digitize the amplified cutting force and $\mathrm{AE}$ sensor signals with sampling frequency $10 \mathrm{kHz}$.

An integrated triaxial vibration sensor (Montronix SpectraPulse) was magnetically attached to the tool holder for the acquisition of the three vibration acceleration components: $a_{x}, a_{y}, a_{z}$. This integrated vibration sensor system included, in addition to the actual sensor and the amplifier, an A/D conversion module with sampling rate of $3 \mathrm{kHz}$. In this way, the vibration acceleration signals were directly sent in digitized form to the PC via USB connection.

\section{Tool wear measurements}

Cutting tool wear measurements were performed using a profile projector (Nikon V-24A) after each $120 \mathrm{~s}$ turning step in order to evaluate the tool condition in terms of flank wear.

Figure 2 shows the tool insert positioning on the profile projector and the tool flank wear visualization and measurement on the profile projector screen.

The tool wear measurement procedure was repeated after each $120 \mathrm{~s}$ turning step until the maximum acceptable flank wear value, $\mathrm{VB}=0.3 \mathrm{~mm}$, was reached. In Figs. 3, 4 and 5, the tool flank wear measurements and the corresponding tool wear interpolated curves are reported for each cutting speed value: $v_{c}=45 \mathrm{~m} / \mathrm{min}$ (Fig. 3), $v_{c}=50 \mathrm{~m} / \mathrm{min}$ (Fig. 4), $\mathrm{v}_{\mathrm{c}}=55 \mathrm{~m} / \mathrm{min}$ (Fig. 5), and the three feed rate values $(0.100$, $0.125,0.150 \mathrm{~mm} / \mathrm{rev})$.

\section{Sensor signal processing}

The detected sensor signals from each turning trial were subjected to a pre-processing phase in order to identify the sensorial information only related to the actual machining (i.e. only when the tool really removes the work material). A signal segmentation procedure [3] was applied to filter out signal segments that do not correspond to actual machining operations. To this scope, the initial and final portions of each sensor signal (cutting force component, $\mathrm{AE}_{\mathrm{RMS}}$, 


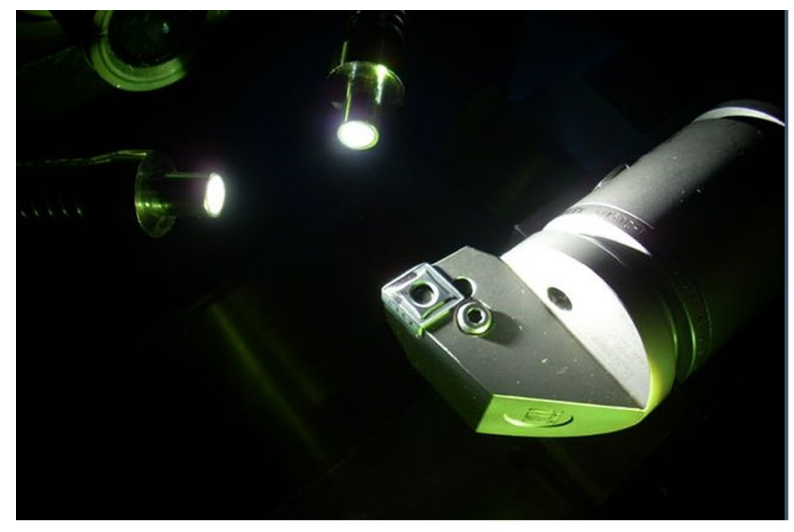

(a)

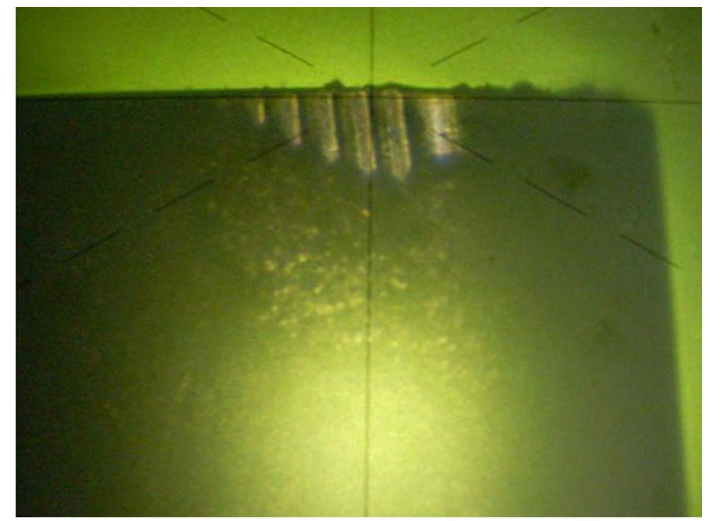

(b)

Fig. 2 a Tool insert positioning and $\mathbf{b}$ tool flank wear visualization on the profile projector

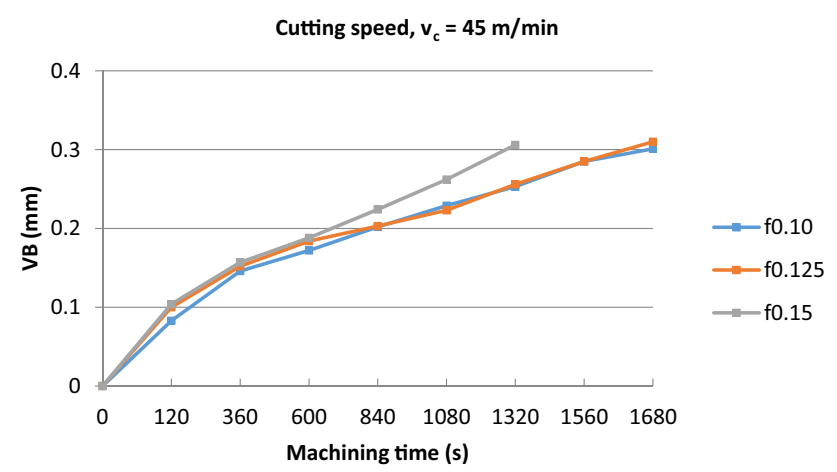

Fig. 3 Tool wear curves for cutting speed $\mathrm{v}_{\mathrm{c}}=45 \mathrm{~m} / \mathrm{min}$ and feed rate $\mathrm{f}=0.100,0.125,0.150 \mathrm{~mm} / \mathrm{rev}$

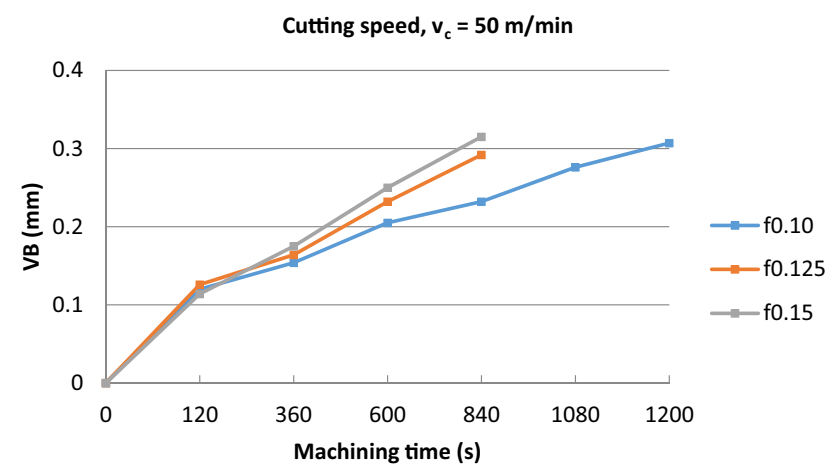

Fig. 4 Tool wear curves for cutting speed $\mathrm{v}_{\mathrm{c}}=50 \mathrm{~m} / \mathrm{min}$ and feed rate $\mathrm{f}=0.100,0.125,0.150 \mathrm{~mm} / \mathrm{rev}$

and vibration acceleration component), related to transient machining conditions (e.g. tool engagement, tool retraction), were eliminated to get rid of misleading information [28, 33, 36].

In Fig. 6, the raw sensor signals for the three cutting force components, $F_{x}, F_{y}$, and $F_{z}$, and the $A_{R M S}$, in the

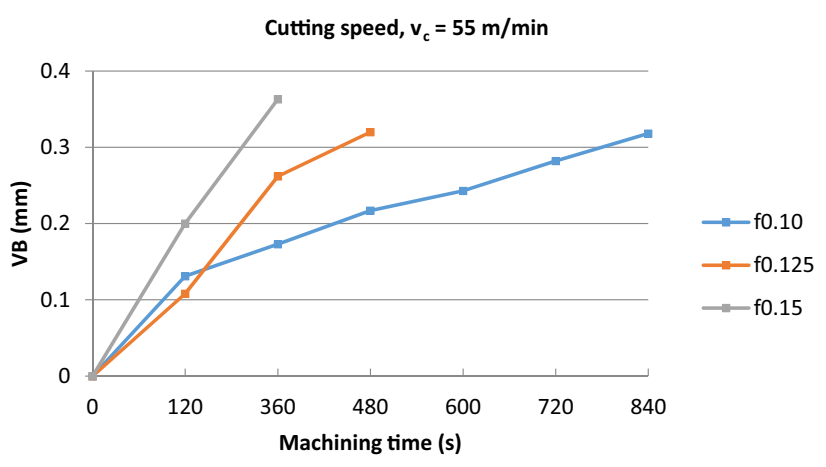

Fig. 5 Tool wear curves for cutting speed $\mathrm{v}_{\mathrm{c}}=55 \mathrm{~m} / \mathrm{min}$ and feed rate $\mathrm{f}=0.100,0.125,0.150 \mathrm{~mm} / \mathrm{rev}$

case of cutting conditions $\mathrm{v}_{\mathrm{c}}=45 \mathrm{~m} / \mathrm{min}$ and $\mathrm{f}=0.100 \mathrm{~mm} /$ rev, are shown together with their segmentation time interval (represented by two dotted vertical red lines) for the removal of the head and tail parts of the sensor signals.

Each segmented signal was subdivided into six equal parts. From each signal subdivision part, one signal specimen of 3000 samplings was extracted. In this way, for each segmented signal, five signal specimens of 3000 samplings were obtained. In Fig. 7, the subdivision of the $F_{x}, F_{y}, F_{z}$ cutting force components into six equal parts is reported, and the five 3000 sampling signal specimens extracted at each separation between signal subdivision parts are represented in yellow.

Thus, a total of 90 signal specimens (9 cutting conditions $\times 2$ repetitions $\times 5$ specimens $=90$ signal specimens) for each tool condition (fresh or worn tool) were obtained for each sensor signal type $\left(F_{x}, F_{y}, F_{z}, A E_{R M S}, a_{x}, a_{y}, a_{z}\right)$. 
Fig. $6 \mathrm{~F}_{\mathrm{x}}, \mathrm{F}_{\mathrm{y}}, \mathrm{F}_{\mathrm{z}}$ and $\mathrm{AE}_{\mathrm{RMS}}$ raw sensor signals and their segmentation time interval (dotted vertical red lines) for the turning trial with $\mathrm{v}_{\mathrm{c}}=45 \mathrm{~m} / \mathrm{min}$ and $\mathrm{f}=0.100 \mathrm{~mm} / \mathrm{rev}$

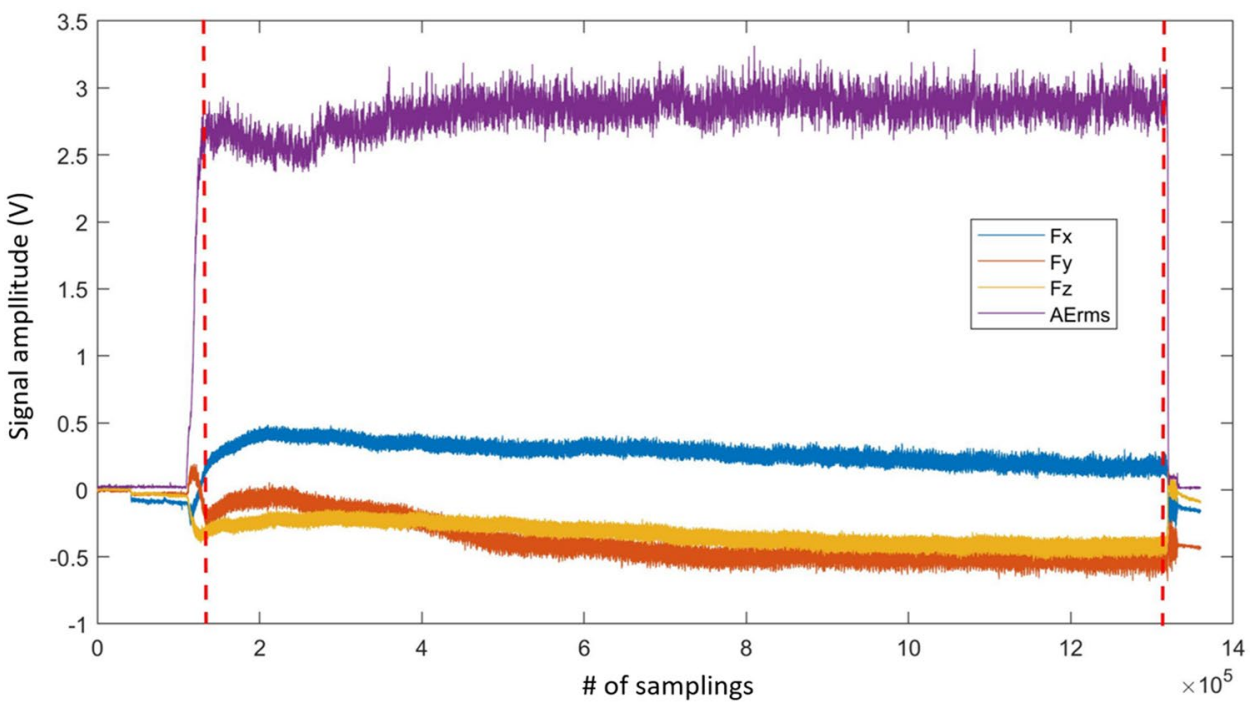

Fig. 7 Cutting force components $F_{x}, F_{y}, F_{z}$ : segmented signal subdivision into six equal parts and extraction of the five 3000 sampling specimens

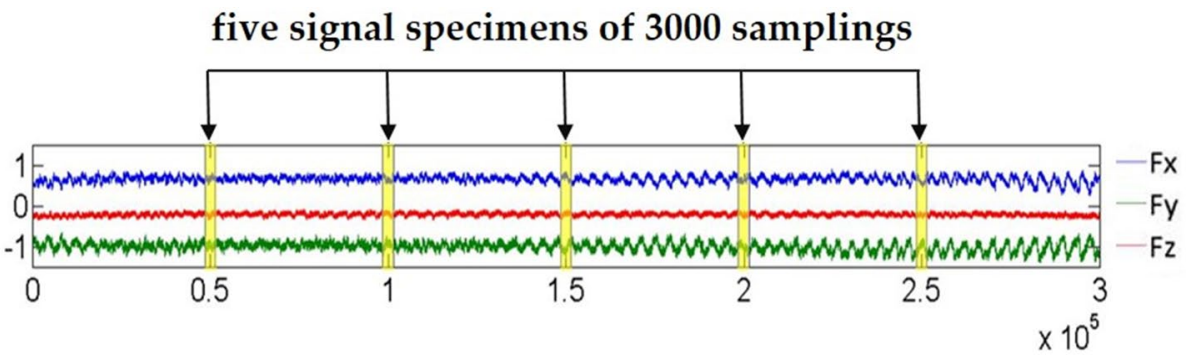

\section{Features extraction using wavelet packet transform}

Wavelet packet transform (WPT) decomposition is a time-frequency domain analysis method which allows to separate relevant information from a sensor signal by scaling and translation procedures generating re-scaled waves, called "wavelets" [15-18]. The implementation of the WPT leads to a tree-structured decomposition, where a signal is passed through low-pass and high-pass filters which are recursively decomposed.

If $\mathrm{f}(\mathrm{t}) \in \mathrm{L}^{2}(\mathrm{R})$ is a signal, $\mathrm{f}(\mathrm{t})$ can be decomposed by using a mother wavelet function, $\psi$ :

$\psi_{s t}(t)=\frac{1}{s} \psi\left(\frac{t-\tau}{s}\right)$

where $s$ is the frequency and $t$ is the time shift.

The wavelet transform of $\mathrm{f}(\mathrm{t})$ is defined by:

$W_{s}[f(\tau)]=\int_{-\infty}^{\infty} f(t) \frac{1}{s} \psi\left(\frac{t-\tau}{s}\right) d t$

$\mathrm{W}_{\mathrm{s}}[\mathrm{f}(\mathrm{t})]$ decomposes a signal $\mathrm{f}(\mathrm{t})$ into a weighted linear combination of a set of scaling functions and wavelet functions at given location $\tau$ and frequency s. The wavelet transform is a time-frequency domain function describing the information of $f(t)$ in various time windows and frequency bands. Wavelet and scaling functions are generated from a single scaling function with two-scale difference equations:

$\varphi(t)=\sqrt{2} \sum_{k} h(k) \varphi(2 t-k)$

$\gamma(t)=\sqrt{2} \sum_{k} g(k) \varphi(2 t-k)$

where $h(k)$ and $g(k)$ are low-pass and high-pass filters coefficients. Coefficients associated with the scaling function (approximation coefficients) are related to low frequency information, while coefficients associated with wavelet function (detail coefficients) capture high-frequency information.

By using Eqs. (3) and (4), a signal can be decomposed at the 1 st level into an approximation $\left(\mathrm{A}_{1}\right)$ and a detail $\left(D_{1}\right)$. At the 2 nd decomposition level, $A_{1}$ and $D_{1}$ are further decomposed into approximations $\left(\mathrm{AA}_{2}\right.$ and $\left.\mathrm{AD}_{2}\right)$ and details $\left(\mathrm{DA}_{2}\right.$ and $\left.\mathrm{DD}_{2}\right)$, and the process is repeated until the selected decomposition level is achieved. The approximation and detail coefficients generated at each level are 
called packets. In Table 5, the wavelet packets generated for a 3rd decomposition level were reported.

In this paper, the WPT analysis was applied to each of the 7 sensor signals types $\left(F_{x}, F_{y}, F_{z}, A_{R M S}, a_{x}, a_{y}, a_{z}\right)$ using a Daubechies 3 as mother wavelet function [18]. The 7 sensor signals were decomposed up to the 3rd level obtaining 14 wavelet packets, for a total number of 98 wavelet packets.

The obtained wavelet coefficients for each packet were treated as separate signals and from them relevant features were extracted. Thus, five statistical features were extracted for each wavelet packet: standard deviation, skewness, kurtosis, root mean square, and energy (Table 6).

For each packet, 35 wavelet features ( 5 statistical features $\times 7$ sensor signals types) were extracted and, in agreement with the 3rd level decomposition, the total number of the extracted signal features was 490 (14 packets $\times 35$ wavelet features per packet).

\section{Selection of features for WPT feature pattern vector construction}

As the number of signal features extracted by the WPT method is very high (490 WPT signal features), a statistical criterion, namely the Pearson's correlation coefficient $\left(\mathrm{r}_{\mathrm{p}}\right)$, was employed to select the relevant WPT features to be utilized in the construction of feature patter vectors (FPVs) for the development of ANNs based ML paradigms for decision making on tool wear conditions.

The Pearson's correlation coefficient is one of the most useful parameters to evaluate the association between the variables of interest, yielding information about the magnitude of the correlation as well as the direction of the relationship [12, 19].

The coefficient $r_{p}$ was employed to measure the correlation between the extracted feature (X) and the output value (Y) using the following equation:

$r_{P}=\frac{1}{N-1} \sum_{i=1}^{N} \frac{\left(X_{i}-\mu_{X}\right)}{\sigma_{X}} \frac{\left(Y_{i}-\mu_{Y}\right)}{\sigma_{Y}}$

where $\mu_{X}, \mu_{Y}$ and $\sigma_{X}, \sigma_{Y}$ are the $\mathrm{X}$ and $\mathrm{Y}$ mean and standard deviation, respectively.

The extracted features (X) correspond to the WPT signal features while the output values $(\mathrm{Y})$ coincide with the
Table 6 Features extracted from each wavelet packet

\begin{tabular}{ll}
\hline Feature & Expression \\
\hline Standard deviation & $\sigma=\sqrt{\frac{1}{N} \sum\left(X_{i}-\mu\right)^{2}}$ \\
Skewness & Skewness $=\frac{E(X-\mu)^{3}}{\sigma^{3}}$ \\
Kurtosis & Kurtosis $=\frac{E(X-\mu)^{4}}{\sigma^{4}}$ \\
Root mean square & $X_{R M S}=\sqrt{\frac{1}{N}\left(X_{1}^{2}+X_{2}^{2}+\ldots+X_{N}^{2}\right)}$ \\
Energy & $X_{\text {ene }}=\log \left(\sum_{i=1}^{N}(X(t))^{2}\right)$ \\
\hline
\end{tabular}

tool wear level. The correlation coefficient $r p$ was judged weak if $0<\left|\mathrm{r}_{\mathrm{p}}\right|<0.3$, moderate if $0.3 \leq\left|\mathrm{r}_{\mathrm{p}}\right|<0.7$, and high if $\left|r_{p}\right| \geq 0.7$.

Figure 8 reports the $r_{p}$ values obtained for each of the 5 statistical WPT features (standard deviation, skewness, kurtosis, root mean square, and energy) calculated for each of the 14 packets and for each of the 7 sensor signal types. As the obtained wavelet packets are 98 , a total of 490 WPT signal features were extracted $(98$ packets $\times 5$ statistical WPT features $=490$ WPT features). To reduce the dimensionality of the extracted features, it is useful to examine Fig. 8 where the WPT signal feature Energy (En) (blue dots in the figure) is shown to be the most correlated feature $\left(\left|r_{p}\right| \geq 0.7\right)$ for each wavelet packet and for each sensor signal type. On this basis, 115 WPT En signal features displaying a correlation value $\geq 0.7$ were selected, which is a much lower number than 490 features.

The selected WPT signal features $($ Energy $=$ En $)$ were used to construct diverse FPVs to be employed in ANNs based ML paradigms for tool wear state estimation. Some of the FPVs were constructed following the sensor fusion approach, i.e. using signal features from sensors of different nature (force, acoustic emission, vibration) [33, 36, 37, 39]. In particular, for each of the 14 WTP packets, the constructed sensor fusion FPVs were:

- 3-element WPT FPV related to the cutting force components; e.g. for packet $A_{1}:\left\{\operatorname{En}\left[A_{1}\right] F_{x}, \operatorname{En}\left[A_{1}\right] F_{y}, \operatorname{En}\left[A_{1}\right]\right.$ $\left.\mathrm{F}_{\mathrm{z}}\right\}$
Table 5 Wavelet packets for the 1st, 2nd, and 3rd decomposition level

\begin{tabular}{|c|c|c|c|c|c|c|c|c|}
\hline Decomposi- & Wavele & cket & & & & & & \\
\hline $1 \mathrm{st}$ & $\mathrm{A}_{1}$ & $\mathrm{D}_{1}$ & & & & & & \\
\hline 2 nd & $\mathrm{AA}_{2}$ & $\mathrm{DA}_{2}$ & $\mathrm{AD}_{2}$ & $\mathrm{DD}_{2}$ & & & & \\
\hline $3 \mathrm{rd}$ & $\mathrm{AAA}_{3}$ & $\mathrm{DAA}_{3}$ & $\mathrm{ADA}_{3}$ & $\mathrm{DDA}_{3}$ & $\mathrm{AAD}_{3}$ & $\mathrm{DAD}_{3}$ & $\mathrm{ADD}_{3}$ & $\mathrm{DDD}_{3}$ \\
\hline
\end{tabular}


Fig. 8 Pearson's coefficient results for each of the 5 statistical WPT signal features: standard deviation, skewness, kurtosis, root mean square, and energy calculated for each of the 14 packets and for each of the 7 sensor signal types

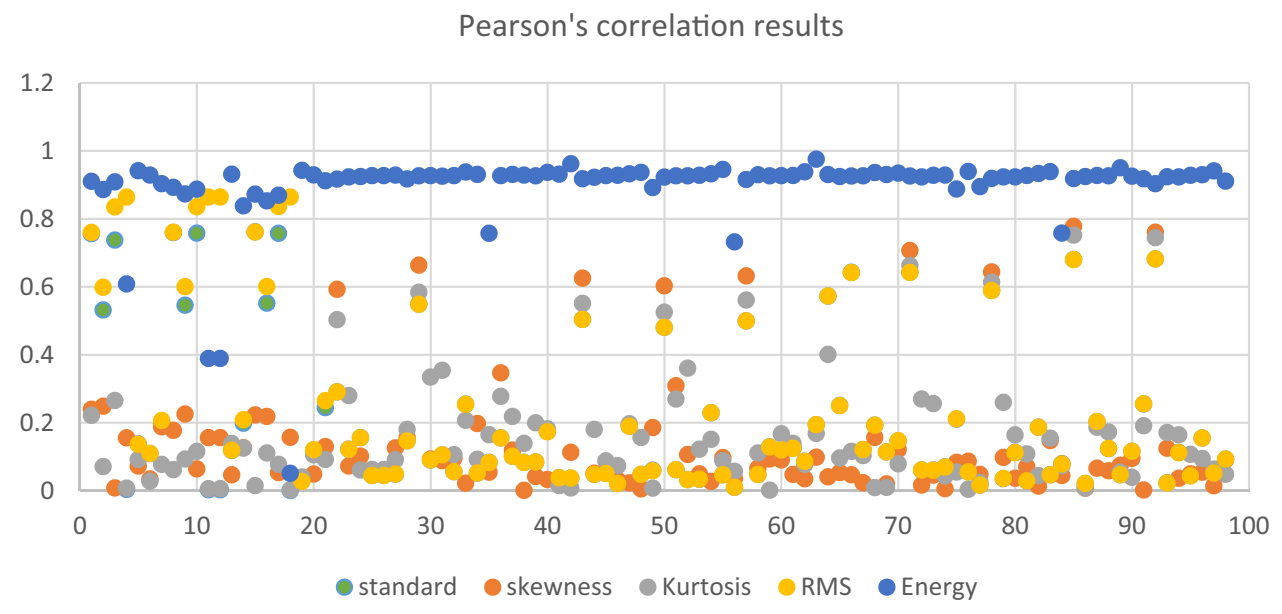

- 3-element WPT FPV related to the vibration acceleration components; e.g. for packet $A_{1}:\left\{\operatorname{En}\left[A_{1}\right] a_{x}, \operatorname{En}\left[A_{1}\right]\right.$ $\left.a_{y}, \operatorname{En}\left[A_{1}\right] a_{z}\right\}$

- 4-element sensor fusion WPT FPV related to the cutting force components and the $\mathrm{AE}_{\mathrm{RMS}}$; e.g. for packet $\mathrm{A}_{1}$ : $\left\{\operatorname{En}\left[\mathrm{A}_{1}\right] \mathrm{F}_{\mathrm{x}}, \operatorname{En}\left[\mathrm{A}_{1}\right] \mathrm{F}_{\mathrm{y}}, \operatorname{En}\left[\mathrm{A}_{1}\right] \mathrm{F}_{\mathrm{z}}, \operatorname{En}\left[\mathrm{A}_{1}\right] \mathrm{AE}_{\mathrm{RMS}}\right\}$

- 4-element sensor fusion WPT FPV related to the vibration acceleration components and the $\mathrm{AE}_{\mathrm{RMS}}$; e.g. for packet $A_{1}:\left\{\operatorname{En}\left[A_{1}\right] a_{x}, \operatorname{En}\left[A_{1}\right] a_{y}, \operatorname{En}\left[A_{1}\right] a_{z}, \operatorname{En}\left[A_{1}\right]\right.$ $\left.\mathrm{AE}_{\mathrm{RMS}}\right\}$

- 7-element sensor fusion WPT FPV combining all sensor signal types; e.g. packet $A_{1}:\left\{\operatorname{En}\left[A_{1}\right] F_{x}, \operatorname{En}\left[A_{1}\right] F_{y}\right.$, $\left.\operatorname{En}\left[\mathrm{A}_{1}\right] \mathrm{F}_{\mathrm{z}}, \operatorname{En}\left[\mathrm{A}_{1}\right] \mathrm{a}_{\mathrm{x}}, \operatorname{En}\left[\mathrm{A}_{1}\right] \mathrm{a}_{\mathrm{y}}, \operatorname{En}\left[\mathrm{A}_{1}\right] \mathrm{a}_{\mathrm{z}}, \operatorname{En}\left[\mathrm{A}_{1}\right] \mathrm{AE}_{\mathrm{RMS}}\right\}$

\section{Artificial neural network based machine learning for tool wear estimation}

Three-layer feed-forward back-propagation artificial neural networks (ANNs), largely utilized for pattern classification tasks [20, 21, 23], were used for the implementation of machine learning paradigms to estimate the cutting tool wear conditions. To build this kind of ANNs, it is first necessary to define the structure of the three network layers (input, hidden and output layers) and then to select the kind of training and learning procedure.

Diverse ANNs configurations were constructed with the input layer containing a number of input nodes equal to the number of elements $(3,4$, or 7 -elements) of the selected WPT FPVs; the output layer had one node corresponding to the tool wear values, while the number of nodes at the hidden layer depends on the number of input layer nodes. In Table 7, the constructed WPT FPVs are reported together with the implemented ANNs configurations.

The ANN training phase was performed using the Levenberg-Marquardt optimization algorithm with the following parameters: the maximum number of the epochs was 1000 ; the performance goal was fixed at 0 ; the minimum performance gradient was set to $1 \times 10^{-7}$; and the maximum $\mathrm{Mu}$ value was fixed at $1 \times 10^{10}$.

For the testing phase, the leave-k-out method [23] with $\mathrm{k}=1$ was applied by removing from the training set one FPV

Table 7 Constructed WPT feature packet vectors and ANNs configurations

\begin{tabular}{|c|c|c|c|}
\hline Sensor signal type & WPT feature pattern vector & $\begin{array}{l}\text { N. of } \\
\text { ele- } \\
\text { ments }\end{array}$ & ANN configuration \\
\hline Cutting force components: $F_{x}, F_{y}, F_{z}$ & $\begin{array}{l}\left.\{\text { En[Packet }] F_{x}, \text { En }[\text { Packet }] F_{y}, \text { En }[\text { Packet }] F_{z}\right\} \text { from each of the } \\
14 \text { WPT packets }\end{array}$ & 3 & $3-3-1 ; 3-6-1$ \\
\hline Vibration acceleration components: $\mathrm{a}_{\mathrm{x}}, \mathrm{a}_{\mathrm{y}}, \mathrm{a}_{\mathrm{z}}$ & $\begin{array}{l}\left.\left.\{\text { En[Packet }] a_{x}, \text { En }[\text { Packet }] a_{y}, \text { En[Packet }\right] a_{z}\right\} \text { from each of the } \\
14 \text { WPT packets }\end{array}$ & 3 & $3-3-1 ; 3-6-1$ \\
\hline \multirow[t]{2}{*}{ Acoustic emission RMS: $\mathrm{AE}_{\mathrm{RMS}}$} & $\begin{array}{l}\left.\left.\{\text { En[Packet }] \mathrm{F}_{\mathrm{x}}, \text { En }[\text { Packet }] \mathrm{F}_{\mathrm{y}}, \text { En[Packet }\right] \mathrm{F}_{\mathrm{z}}, \text { En[Packet }\right] \\
\left.\mathrm{AE}_{\mathrm{RMS}}\right\} \text { from each of the } 14 \text { WPT packets }\end{array}$ & 4 & $4-4-1 ; 4-8-1$ \\
\hline & $\begin{array}{l}\left.\left.\text { En[Packet }] a_{x}, E n[\text { Packet }] a_{y}, \text { En[Packet }\right] a_{z}, \text { En }[\text { Packet }] \mathrm{AE}_{\mathrm{RMS}}\right\} \\
\text { from each of the } 14 \text { WPT packets }\end{array}$ & 4 & $4-4-1 ; 4-8-1$ \\
\hline All sensor signal types: $F_{x}, F_{y}, F_{z}, a_{x}, a_{y}, a_{z}, A_{R M S}$ & $\begin{array}{l}\left.\{\text { En[Packet }] F_{i}(i=x, y, z) ; \text { En[Packet }\right] a_{j}(i=x, y, z) \\
\left.\text { En[Packet }] E_{\text {RMS }}\right\} \text { from each of the } 14 \text { WPT packets }\end{array}$ & 7 & $7-7-1 ; 7-14-1$ \\
\hline
\end{tabular}


at a time, in order to use it as test case, whereas the remaining FPVs were employed for ANN training.

\section{Results and discussion}

The ANNs performance was evaluated using the mean absolute percentage error (MAPE), i.e. the absolute difference between target tool wear value $(z)$ and ANN predicted value $\left(\hat{z}_{t}\right)$ divided by the tool wear actual value, as defined by:

MAPE $=\frac{100}{n} \sum_{t=1}^{n}\left|\frac{z_{t}-\hat{z}_{t}}{z_{t}}\right|$

In Figs. 9, 10, 11, 12 and 13 and Table 8, the ANN MAPE results $(\%)$ for each of the 14 wavelet packets are reported for:
- 3-element FPV associated to the three cutting force components $\mathrm{F}_{\mathrm{x}}, \mathrm{F}_{\mathrm{y}}, \mathrm{F}_{\mathrm{z}}$ (Fig. 9).

- 3-element FPV associated the three vibration acceleration components $\mathrm{a}_{\mathrm{x}}, \mathrm{a}_{\mathrm{y}}, \mathrm{a}_{\mathrm{z}}$ (Fig. 10).

- 4-element sensor fusion FPV associated to the three cutting force components and the $\mathrm{AE}_{\mathrm{RMS}}$ (Fig. 11).

- 4-element sensor fusion FPV associated to the three vibration acceleration components and the $A E_{\mathrm{RMS}}$ (Fig. 12).

- 7-element sensor fusion FPV combining all sensor signal types (Fig. 13).

From Figs. 9, 10, 11, 12 and 13 and Table 8, it can be noted that very low ANN MAPE values were achieved for all WPT packets and for all the constructed WPT FPVs with an average value ranging from 5.17 to $7.73 \%$, which denotes
Fig. 9 ANN MAPE results for the 3-element WPT FPV related to $\left\{F_{x}, F_{y}, F_{z}\right\}$ for each of the 14 wavelet packets with a number of hidden nodes equal to 3 and 6
Fig. 10 ANN MAPE results for the 3-element WPT FPV related to $\left\{a_{x}, a_{y}, a_{z}\right\}$ for each of the 14 wavelet packets with a number of hidden nodes equal to 3 and 6

\section{3-element WPT FPV for the 3 cutting force components}

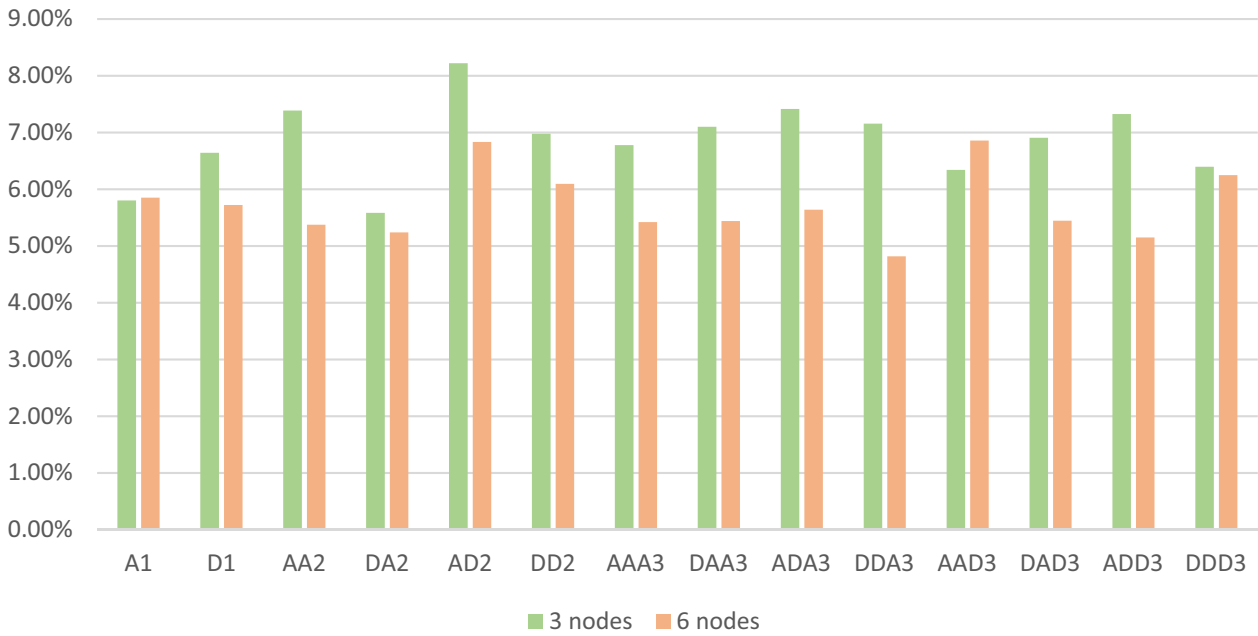

3-element WPT FPV for the 3 vibration acceleration components

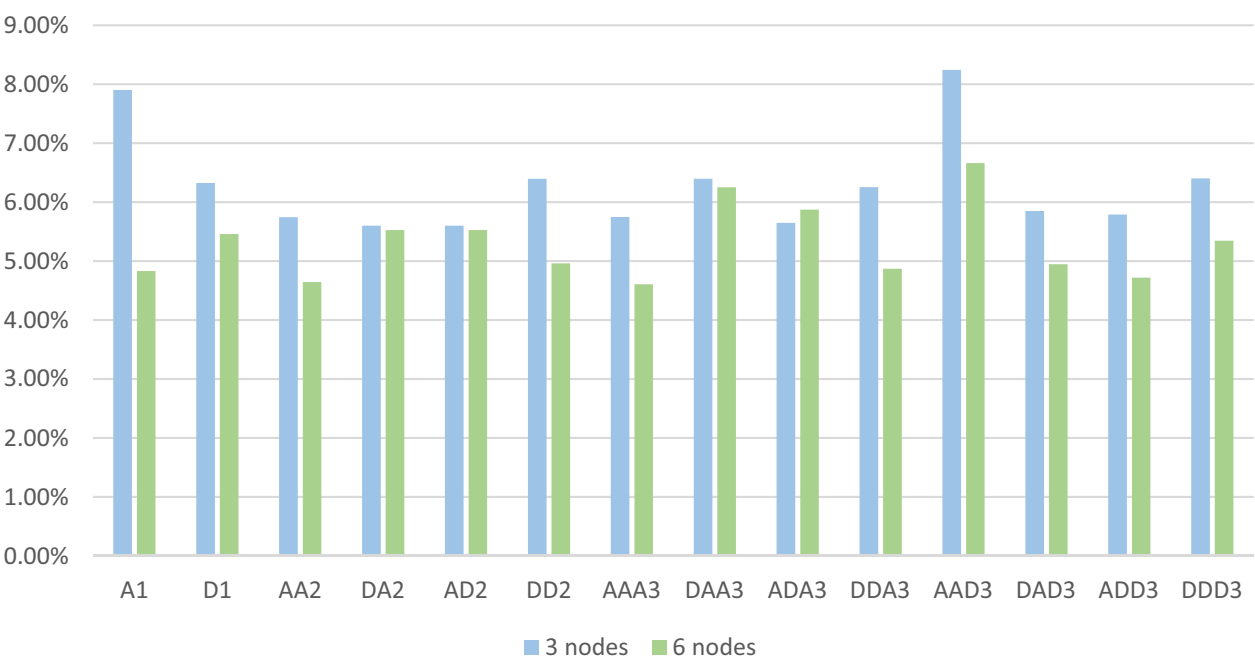


Fig. 11 ANN MAPE results for the 4-element sensor fusion WPT FPV related to $\left\{F_{x}, F_{y}\right.$, $\left.\mathrm{F}_{\mathrm{z}}, \mathrm{AE}_{\mathrm{RMS}}\right\}$ for each of the 14 wavelet packets with a number of hidden nodes equal to 4 and 8

Fig. 12 ANN MAPE results for the 4-element sensor fusion WPT FPV related to $\left\{a_{x}, a_{y}\right.$, $\left.a_{z}, A_{\text {RMS }}\right\}$ for each of the 14 wavelet packets with a number of hidden nodes equal to 4 and 8

Fig. 13 ANN MAPE results for the 7-element sensor fusion WPT FPV related to $\left\{\mathrm{F}_{\mathrm{x}}, \mathrm{F}_{\mathrm{y}}\right.$, $\left.\mathrm{F}_{\mathrm{z}}, \mathrm{a}_{\mathrm{x}}, \mathrm{a}_{\mathrm{y}}, \mathrm{a}_{\mathrm{z}}, \mathrm{AE}_{\mathrm{RMS}}\right\}$ for each of the 14 wavelet packets with a number of hidden nodes equal to 7 and 14 4-element sensor fusion WPT FPV for the 3 cutting force components and $A E_{\text {RMS }}$

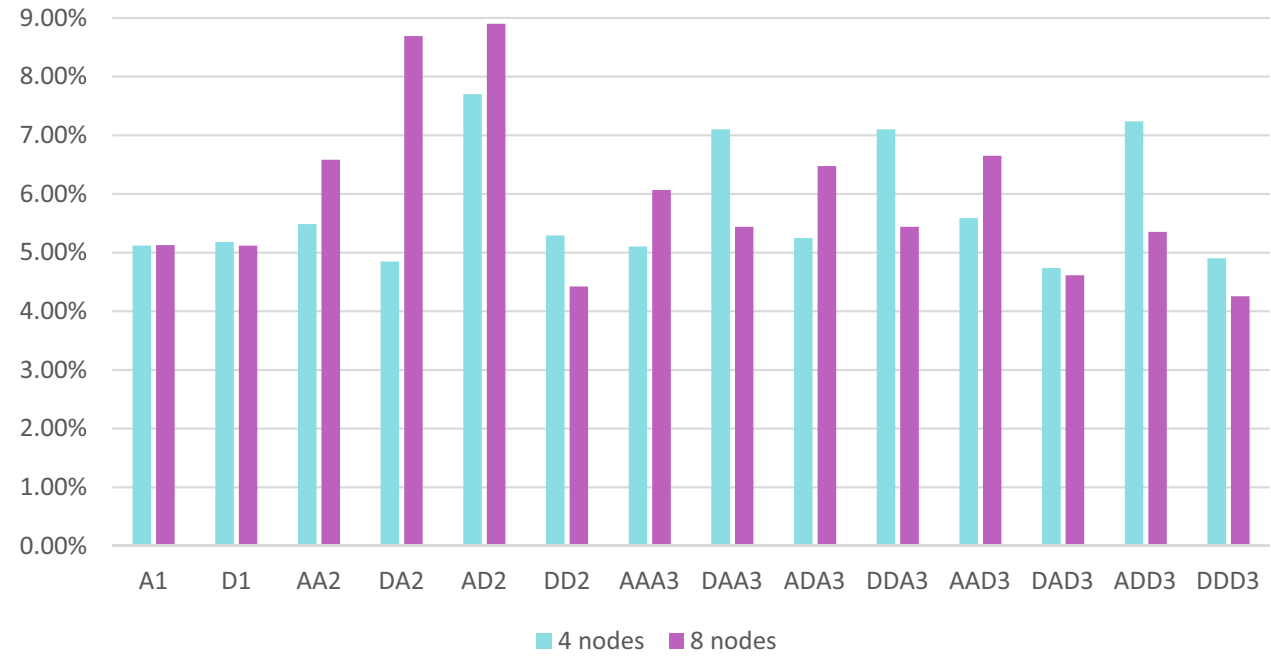

\section{4-element sensor fusion WPT FPV for the 3 vibration components and $A E_{R M S}$}

$9.00 \%$

$8.00 \%$

$7.00 \%$

$6.00 \%$

$5.00 \%$

$4.00 \%$

$3.00 \%$

$2.00 \%$

$1.00 \%$

$0.00 \%$

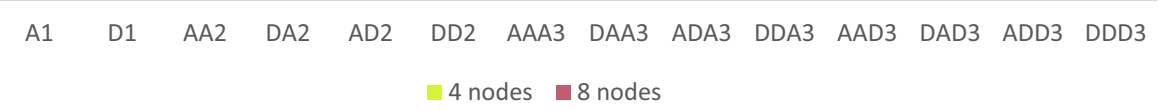

7-element sensor fusion WPT FPV combining all 7 sensor signal types

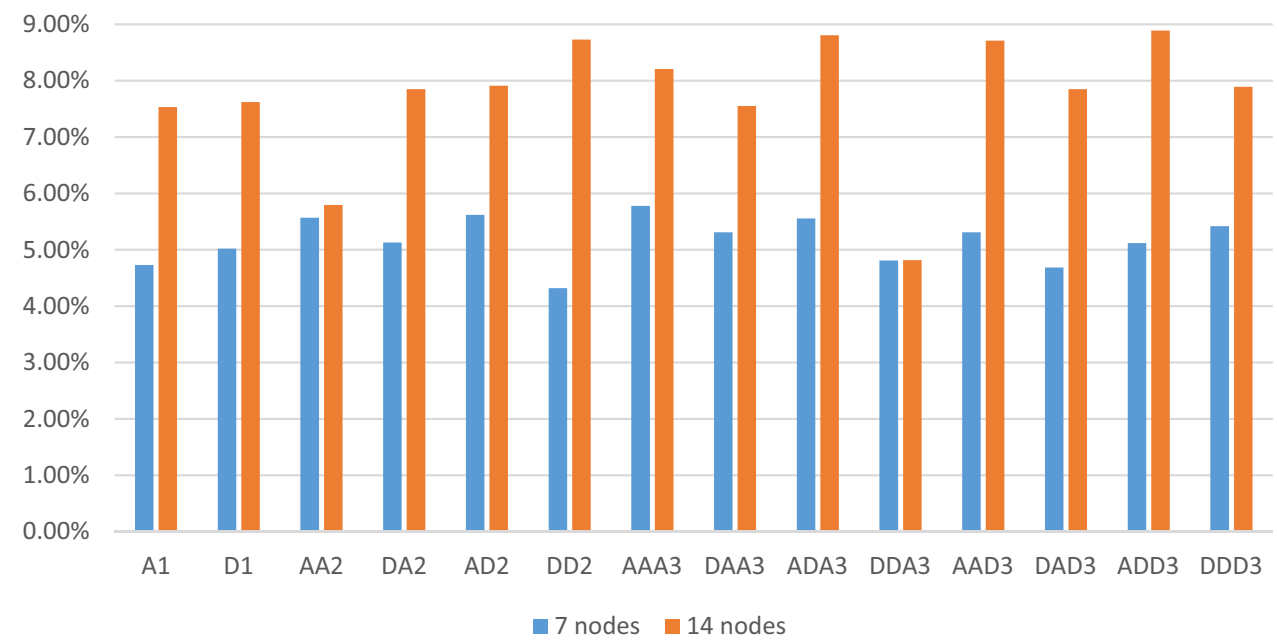


Table 8 ANN MAPE results (\%) for each WPT packet by considering the diverse WPT FPVs and ANN models

\begin{tabular}{|c|c|c|c|c|c|c|c|c|c|c|c|}
\hline \multirow{2}{*}{$\begin{array}{l}\text { WPT FPV } \\
\text { ANN model }\end{array}$} & \multicolumn{2}{|c|}{$\begin{array}{l}\text { 3-element } \\
\text { FPV: }\left\{F_{x}, F_{y},\right. \\
\left.F_{z}\right\}\end{array}$} & \multicolumn{2}{|c|}{$\begin{array}{l}\text { 3-element } \\
\text { FPV: }\left\{a_{x}, a_{y},\right. \\
\left.a_{z}\right\}\end{array}$} & \multicolumn{2}{|c|}{$\begin{array}{l}\text { 4-element } \\
\text { sensor fusion } \\
\text { FPV: }\left\{F_{x}, F_{y} \text {, }\right. \\
\left.F_{z}, A_{R_{R M S}}\right\}\end{array}$} & \multicolumn{2}{|c|}{$\begin{array}{l}\text { 4-element } \\
\text { sensor fusion } \\
\text { FPV: }\left\{a_{x}, a_{y},\right. \\
\left.a_{z}, A_{\text {RMS }}\right\}\end{array}$} & \multicolumn{2}{|c|}{$\begin{array}{l}\text { 7-element } \\
\text { sensor fusion } \\
\text { FPV: }\left\{\mathrm{F}_{\mathrm{x}}, \mathrm{F}_{\mathrm{y}},\right. \\
\mathrm{F}_{\mathrm{z}}, \mathrm{a}_{\mathrm{x}}, \mathrm{a}_{\mathrm{y}}, \mathrm{a}_{\mathrm{z}} \\
\left.\mathrm{AE}_{\mathrm{RMS}}\right\}\end{array}$} & \multirow[t]{2}{*}{ Packet average } \\
\hline & $3-3-1$ & $3-6-1$ & $3-3-1$ & $3-6-1$ & $4-4-1$ & $4-8-1$ & $4-4-1$ & $4-8-1$ & $7-7-1$ & $7-14-1$ & \\
\hline $\mathrm{A}_{1}$ & 5.80 & 5.85 & 7.90 & 4.83 & 5.12 & 5.13 & 5.04 & 3.97 & 4.73 & 7.53 & 5.59 \\
\hline $\mathrm{D}_{1}$ & 6.64 & 5.72 & 6.33 & 5.46 & 5.18 & 5.12 & 5.01 & 5.20 & 5.02 & 7.62 & 5.73 \\
\hline $\mathrm{AA}_{2}$ & 7.39 & 5.37 & 5.75 & 4.64 & 5.48 & 6.58 & 5.07 & 5.08 & 5.57 & 5.79 & 5.67 \\
\hline $\mathrm{DA}_{2}$ & 5.58 & 5.24 & 5.60 & 5.53 & 4.85 & 8.69 & 5.17 & 5.97 & 5.13 & 7.85 & 5.96 \\
\hline $\mathrm{AD}_{2}$ & 8.22 & 6.84 & 5.60 & 5.53 & 7.70 & 8.90 & 5.60 & 5.53 & 5.62 & 7.91 & 6.75 \\
\hline $\mathrm{DD}_{2}$ & 6.98 & 6.10 & 6.39 & 4.96 & 5.29 & 4.42 & 4.77 & 5.71 & 4.32 & 8.73 & 5.77 \\
\hline $\mathrm{AAA}_{3}$ & 6.78 & 5.42 & 5.75 & 4.61 & 5.11 & 6.07 & 5.11 & 6.65 & 5.78 & 8.21 & 5.95 \\
\hline $\mathrm{DAA}_{3}$ & 7.10 & 5.44 & 6.40 & 6.25 & 7.10 & 5.44 & 5.43 & 4.63 & 5.31 & 7.55 & 6.07 \\
\hline $\mathrm{ADA}_{3}$ & 7.42 & 5.64 & 5.65 & 5.87 & 5.25 & 6.48 & 5.65 & 5.87 & 5.56 & 8.81 & 6.22 \\
\hline $\mathrm{DDA}_{3}$ & 7.16 & 4.82 & 6.25 & 4.87 & 7.10 & 5.44 & 6.55 & 4.35 & 4.81 & 4.82 & 5.62 \\
\hline $\mathrm{AAD}_{3}$ & 6.34 & 6.86 & 8.24 & 6.66 & 5.59 & 6.65 & 7.63 & 5.86 & 5.31 & 8.71 & 6.79 \\
\hline $\mathrm{DAD}_{3}$ & 6.91 & 5.45 & 5.85 & 4.95 & 4.74 & 4.61 & 6.61 & 6.75 & 4.68 & 7.85 & 5.84 \\
\hline $\mathrm{ADD}_{3}$ & 7.32 & 5.15 & 5.79 & 4.72 & 7.24 & 5.35 & 5.79 & 4.72 & 5.12 & 8.89 & 6.01 \\
\hline $\mathrm{DDD}_{3}$ & 6.40 & 6.25 & 6.40 & 5.35 & 4.90 & 4.26 & 6.40 & 5.35 & 5.42 & 7.89 & 5.86 \\
\hline FPV average & 6.86 & 5.73 & 6.28 & 5.30 & 5.76 & 5.94 & 5.70 & 5.40 & 5.17 & 7.73 & \\
\hline
\end{tabular}

the high capability of the implemented ANNs to provide an accurate tool wear estimation.

As regards the MAPE values obtained considering the 3-element WPT FPVs associated to the three cutting force components $\mathrm{F}_{\mathrm{x}}, \mathrm{F}_{\mathrm{y}}, \mathrm{F}_{\mathrm{z}}$ (Fig. 9, Table 8) and the three vibration acceleration components $\mathrm{a}_{\mathrm{x}}, \mathrm{a}_{\mathrm{y}}, \mathrm{a}_{\mathrm{z}}$ (Fig. 10, Table 8), the lowest average MAPE value $\left(\mathrm{MAPE}_{\mathrm{ave}}=5.30 \%\right)$ was obtained for the 3-element FPV related to $a_{x}, a_{y}, a_{z}$ with ANN configuration 3-6-1, whereas the three cutting force components showed average MAPE values between $5.73 \%$ (3-6-1 ANN configuration) and 6.86\% (3-3-1 ANN configuration).

The 4-element sensor fusion WPT FPV associated to the cutting force components plus the $\mathrm{AE}_{\mathrm{RMS}}$ (Fig. 11, Table 8,) and the vibration acceleration components plus the $A_{\mathrm{RMS}}$ (Fig. 12, Table 8) showed slightly lower average MAPE values than the 3-element WPT FPVs.

The best performance in tool wear estimation was obtained by considering all the sensor signal types in the 7-element sensor fusion WPT FPV (MAPE $\left.{ }_{\text {ave }}=5.17 \%\right)$ with ANN configuration 7-7-1 (Fig. 13, Table 8). In this case, the increase of the number of hidden nodes in the 7-14-1 configuration reduced the ANNs performance, differently from all other cases, which might be caused by a too high number of hidden nodes (14).

By analysing the performance of the 14 wavelet packets (in terms of packet MAPE average value) for all the considered WPT FPVs and all the implemented ANNs configurations (Table 8), the $A_{1}$ packet at the 1 st decomposition level provided the best average MAPE value equal to $5.59 \%$, followed by the $\mathrm{DDA}_{3}$ packet at the 3rd decomposition level $\left(\mathrm{MAPE}_{\mathrm{ave}}=5.62 \%\right)$ and the $\mathrm{AA}_{2}$ packet $\left(\mathrm{MAPE}_{\mathrm{ave}}=5.67 \%\right)$ at the 2 nd decomposition level. The worst performance was obtained for the $\mathrm{AAD}_{3}$ packet $\left(\mathrm{MAPE}_{\mathrm{ave}}=6.79 \%\right)$ at the $3 \mathrm{rd}$ decomposition level.

\section{Conclusions}

The goal of this paper was to provide a tool wear estimation method during turning of hard-to-machine Inconel 718. For this purpose, three types of sensors (cutting force, acoustic emission, and vibration sensor) were mounted on the tool holder as near as possible to the tool cutting edge for the detection of sensorial data generated by the cutting process. The acquired sensor signals were pre-processed and analyzed using wavelet packet transform (WPT) decomposition to extract time-frequency domain signal features. After each two-minutes turning step, the cutting tool flank wear was measured to evaluate the tool condition. A Pearson's coefficient algorithm was adopted to select the WPT signal features most correlated with the tool wear level in order to reduce the high dimensionality of the obtained WPT features. The selected WPT signal features were utilized to construct diverse feature pattern vectors (FPV), including instances of sensor fusion FPVs, to feed to artificial neural networks (ANNs) for decision making on tool condition.

The performance of the ANN models was evaluated using the mean absolute percentage error (MAPE), and the results showed that the ANN outputs were in all cases in very good 
agreement with the measured flank wear values, confirming the capability of the ANNs in providing an accurate tool wear estimation based on multiple sensor monitoring. In particular, the best ANNs performance was obtained with the 7-element sensor fusion WPT FPV, related to all the 7 sensor signal types, yielding an average MAPE value equal to $5.17 \%$ in the case of the 7-7-1 ANN architecture.

The accurate tool wear estimation achieved through the application of wavelet sensor signal analysis and ANNbased machine learning paradigms presented in this paper can allow for the realization of an effective intelligent tool condition monitoring system during turning of Inconel 718.

Acknowledgements The Fraunhofer Joint Laboratory of Excellence on Advanced Production Technology (Fh J_LEAPT UniNaples) at the Department of Chemical, Materials and Industrial Production Engineering, University of Naples Federico II, is gratefully acknowledged for its contribution and support to this research activity.

Funding Open access funding provided by Università degli Studi di Napoli Federico II within the CRUI-CARE Agreement.

Open Access This article is licensed under a Creative Commons Attribution 4.0 International License, which permits use, sharing, adaptation, distribution and reproduction in any medium or format, as long as you give appropriate credit to the original author(s) and the source, provide a link to the Creative Commons licence, and indicate if changes were made. The images or other third party material in this article are included in the article's Creative Commons licence, unless indicated otherwise in a credit line to the material. If material is not included in the article's Creative Commons licence and your intended use is not permitted by statutory regulation or exceeds the permitted use, you will need to obtain permission directly from the copyright holder. To view a copy of this licence, visit http://creativecommons.org/licenses/by/4.0/.

\section{References}

1. Gupta MK, Mia M, Pruncu CI, Kapłonek W, Nadolny K, Patra K, Mikolajczyk T, Pimenov DY, Sarikaya M, Sharma VS (2009) Parametric optimization and process capability analysis for machining of nickel-based superalloy. Int J Adv Manuf Technol 102:3995-4009

2. Ezugwu EO (2005) Key improvements in the machining of difficult-to-cut aerospace superalloys. Int J Mach Tools Manuf 45:1353-1367

3. Akhavan NF, Ulutan D, Mears L (2016) Parameter inference under uncertainty in end-milling $\gamma$-strengthened difficult-to-machine alloy. J Manuf Sci Eng 138:1

4. Ulutan D, Ozel T (2011) Machining induced surface integrity in titanium and nickel alloys: a review. Int J Mach Tools Manuf $51: 250-280$

5. Dudzinski D, Devillez A, Moufki A, Larrouquère D, Zerrouki V, Vigneau J (2004) A review of developments towards dry and high speed machining of Inconel 718 alloy. Int J Mach Tools Manuf 44:439-456

6. Cantero JL, Díaz-Álvarez J, Miguélez MH, Marín NC (2013) Analysis of tool wear patterns in finishing turning of Inconel 718. Wear 297:885-894
7. Marques A, Paipa Suarez M, Falco Sales W, Rocha Machado Á (2019) Turning of Inconel 718 with whisker-reinforced ceramic tools applying vegetable-based cutting fluid mixed with solid lubricants by MQL. J Mater Process Technol 266:530-543

8. D'Addona D, Segreto T, Simeone A, Teti R (2011) ANN tool wear modelling in the machining of nickel superalloy industrial products. CIRP J Manuf Sci Tech 4(1):33-37

9. Yılmaz B, Karabulut Ş, Güllü A (2018a) Performance analysis of new external chip breaker for efficient machining of Inconel 718 and optimization of the cutting parameters. J Manuf Proc 32:553-563

10. Zhu D, Zhang X, Ding H (2013) Tool wear characteristics in machining of nickel-based superalloys. Int J Mach Tool Manuf 64:60-77

11. Byrne G, Dornfeld D, Inasaki I, Ketteler G, Konig W, Teti R (1995) Tool condition monitoring (TCM) - the status of research and industrial application. Ann CIRP 44:541

12. Dimla DE (2000) Sensor signal for tool-wear monitoring in metal cutting operations - a review of methods. Int J Mach Tool Manuf 40:1073-1098

13. Liang SY, Rogelio LH, Robert GL (2004) Machining process monitoring and control: the state-of-the-art. J Manuf Sci Eng 126:297-310

14. Teti R, Jemielniak K, O’Donnell G, Dornfeld D (2010) Advanced monitoring of machining operations. CIRP Ann 59(2):717-739

15. Ahmed YS, Arif AFM, Veldhuis SC (2020) Application of the wavelet transform to acoustic emission signals for built-up edge monitoring in stainless steel machining. Measurement 154:107478

16. Olortegui-Yume JA, Kwon PY (2010) Crater wear patterns analysis on multi-layer coated carbides using the wavelet transform. Wear 268:493-504

17. Dutta S, Pal SK, Sen R (2016) Progressive tool flank wear monitoring by applying discrete wavelet transform on turned surface images. Meas J Int Meas Confed 77:388-401

18. Zhu K, Wong YS, Hong GS (2009) Wavelet analysis of sensor signals for tool condition monitoring: a review and some new results. Int J Mach Tool Manuf 49(7/8):537-553

19. Xie Z, Li J, Lu Y (2019) Feature selection and a method to improve the performance of tool condition monitoring. Int $\mathrm{J}$ Adv Manuf Technol 100:3197-3206

20. Alpaydin E (2014) Introduction to machine learning. MIT Press, USA

21. Balazinski M, Czogala E, Jemielniak K, Leski J (2002) Tool condition monitoring using artificial intelligence methods. Eng Appl Art Intell 15(1):73-80

22. Zhou Y, Xue W (2018) Review of tool condition monitoring methods in milling processes. Int J Adv Manuf Technol 96:2509-2523

23. Segreto T, Teti R (2019) Machine learning for in-process endpoint detection in robot-assisted polishing using multiple sensor monitoring. Int J AdvManuf Tech 103(9-12):4173-4187

24. Li S, Elbestawi MA (1996) Fuzzy clustering for automated tool condition monitoring in machining. Mech Syst Sign Proc 10(5):533-550

25. Pandiyan V, Caesarendra W, Tjahjowidodo T, Tan HH (2018) In-process tool condition monitoring in compliant abrasive belt grinding process using support vector machine and genetic algorithm. J Manuf Proc 31:199-213

26. Yu G, Li C, Sun J (2010) Machine fault diagnosis based on Gaussian mixture model and its application. Int J Adv Manuf Technol 48:205-212

27. Kothamasu R, Huang SH, Verduin WH (2005) Comparison of computational intelligence and statistical methods in condition monitoring for hard turning. Int J Prod Res 43(3):597-610

28. Segreto T, Caggiano A, Karam S, Teti R (2017) Vibration sensor monitoring of nickel-titanium alloy turning for machinability evaluation. Sensors 17(12):2885 
29. Owsley LMD, Atlas LE, Bernard GD (1997) Self-organizing feature maps and hidden Markov models for machine-tool monitoring. IEEE Trans Sign Proc 45(11):2787-2796

30. Baruah P, Chinnam RB (2005) HMMs for diagnostics and prognostics in machining processes. Int J Prod Res 43(6):1275-1293

31. Kong D, Chen Y, Li N, Duan C, Lu L, Chen D (2019) Relevance vector machine for tool wear prediction. Mech Syst Sig Proc 127:573-594

32. Tanaka H, Sugihara T, Enomoto T (2016) High speed machining of Inconel 718 focusing on wear behaviors of PCBN cutting tool. Proc CIRP 46:545-548

33. Segreto T, Simeone A, Teti R (2013) Multiple sensor monitoring in nickel alloy turning for tool wear assessment via sensor fusion. Proc CIRP 12:85-90

34. Thakur A, Gangopadhyay S (2016) State-of-the-art in surface integrity in machining of nickel-based super alloys. Int J Mach Tool Manuf 100:25-54

35. Niaki FA, Mears L (2017) A comprehensive study on the effects of tool wear on surface roughness, dimensional integrity and residual stress in turning IN718 hard-to-machine alloy. J Manuf Proc 30:268-280

36. Simeone A, Segreto T, Teti R (2013) Residual stress condition monitoring via sensor fusion in turning of Inconel 718. Proc CIRP $12: 67-72$
37. Mali R, Telsang MT, Gupta TVK (2017) Real time tool wear condition monitoring in hard turning of Inconel 718 using sensor fusion system. Mat Tod: Proc 4(8):8605-8612

38. Grzesik W, Niesłony P, Habrat W, Sieniawski J, Laskowski P (2018) Investigation of tool wear in the turning of Inconel 718 superalloy in terms of process performance and productivity enhancement. Trib Int 118:337-346

39. Kene AP, Choudhury SK (2019) Analytical modeling of tool health monitoring system using multiple sensor data fusion approach in hard machining. Meas 145:118-129

40. Yılmaz B, Karabulut Ş, Güllü A (2018b) Performance analysis of new external chip breaker for efficient machining of Inconel 718 and optimization of the cutting parameter. J Manuf Proc 32:553-563

Publisher's Note Springer Nature remains neutral with regard to jurisdictional claims in published maps and institutional affiliations. 